
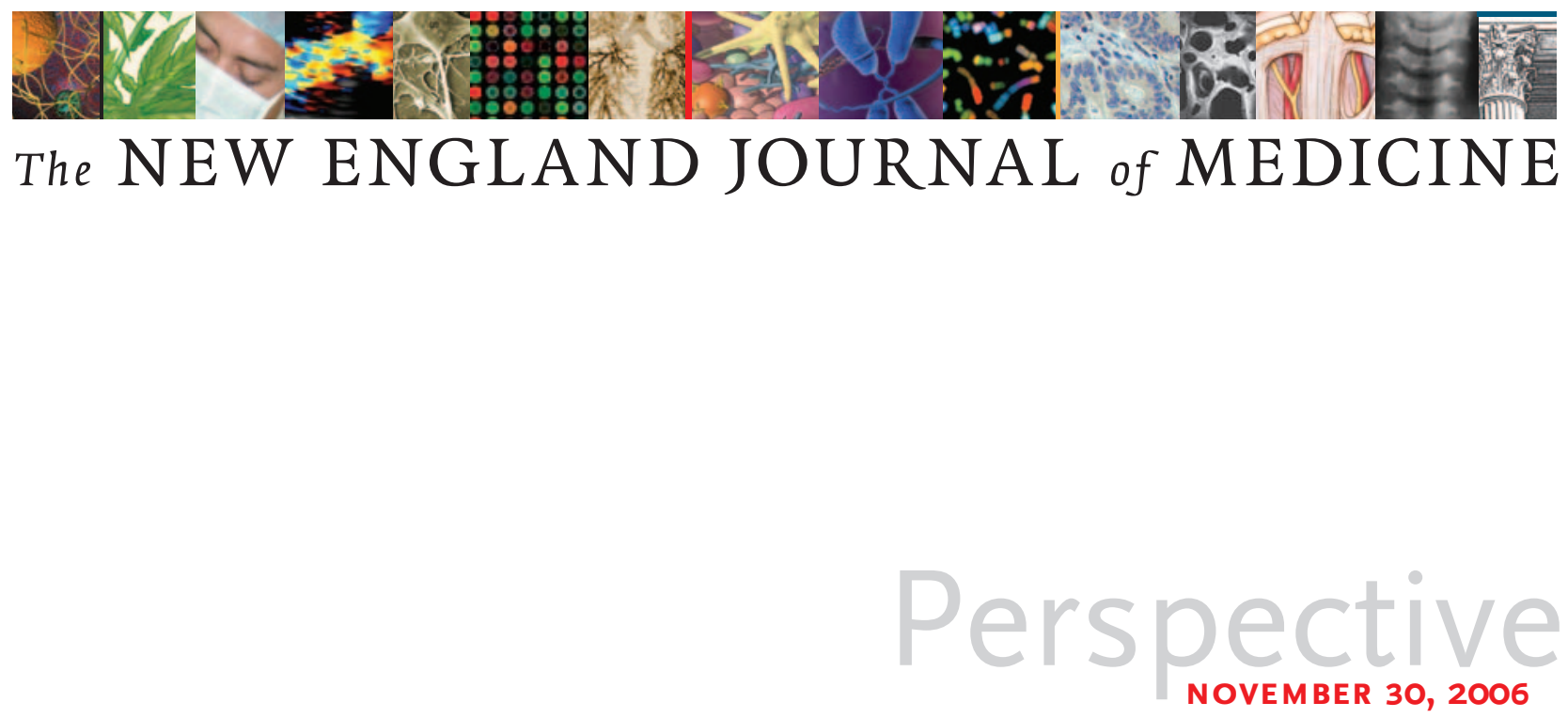

\title{
Pioneers in AIDS Care - Reflections on the Epidemic's Early Years
}

Ronald Bayer, Ph.D., and Gerald M. Oppenheimer, Ph.D., M.P.H.

\section{Tn 1995, Constance Wofsy, who had been a leader Iin San Francisco's response to AIDS in the 1980s, recalled the way she and other physicians had been drawn to the nascent epidemic. "How gripped we}

were," she said, "How separate we were from everyone who wasn't part of the thing. There were the involved and uninvolved, and they just didn't understand one another."

In July, a tape recording of these recollections, made a year before Wofsy's death, was heard by 17 doctors who had come together in New York to commemorate the 25th anniversary of the first reported AIDS cases. The participants were among 76 first-generation AIDS doctors whom we had interviewed in the 1990s for an oral history documenting the U.S. epidemic. ${ }^{1}$ At the day-long July meeting, they looked back on their work, shared memories of the darkest years, recalled the exhilaration of the first prospects for effective AIDS treatment, and ruminated about who would step in to care for future patients.

The group vividly recalled pervasive institutional and professional resistance to caring for patients with AIDS during the early 1980s. How could they explain why they had decided to take on this burden - a decision that had shaped their lives in unanticipated ways? At the time, most were young and beginning their careers, unencumbered by established commitments. But there was more to it than that. For gay and lesbian doctors, the suffering in their community provided sufficient motivation. For others, the AIDS crisis tapped into long-held views about the social mission of medicine and the need to care for the marginal- ized and despised. Wafaa El-Sadr, who developed the AIDS program at Harlem Hospital, said the epidemic had opened new worlds to her by demonstrating the importance of engaging in a genuine way with patients and drawing on their strengths.

Many felt compelled by geography: being in New York, Los Angeles, San Francisco, or Miami made the epidemic hard to ignore. Pediatrician James Oleske remembers feeling that in the impoverished community of Newark, New Jersey, he had no alternative but to care for babies and children with AIDS.

One thread that ran through the varied explanations was a deep sense of duty - of the doctor's moral responsibility. In 1981, Molly Cooke, a San Francisco physician, was pregnant with her first child. Given how little was known about the risk of transmission, she was understandably fearful of taking on patients with AIDS. Yet she 
remembered saying to her husband, Paul Volberding, an oncologist who would help to shape San Francisco General Hospital's response to AIDS, "If not us, who? What's the justification for saying someone else should do this?"

Whatever induced these physicians to make the initial commitment, perhaps a more difficult question is what sustained their engagement in patient care and advocacy in an era when medicine was all but impotent against AIDS.

Some, like Donna Mildvan, an infectious-disease specialist in New York, felt a strong need to "bear witness; we were seeing stuff that nobody else in the world was seeing." Through clinical treatment and careful observation, she be- you hated what was happening, and it was that love that kept you there and keeps me there." Like Mendez, Gerald Friedland, who worked with drug users in the Bronx, remembered the emotional draw: "The kind of suffering that people endured and the cour- lier time of medicine" - to an era when the doctor was more magician than scientist. Simple acts such as holding patients' hands and listening to their stories were critical. Those who cared for poor patients, including drug users and their families, say the demands

I was in Newark, New Jersey. I was committed to working in an underserved area. I love children. All I remember was that there was one sick child after another coming in. It wasn't a conscious decision that I wanted to work with AIDS or not work with AIDS. It was there, and you had to do it. You didn't have a choice.

age that most of our patients actually had [were] extraordinary and inspired me."

These physicians also found their commitment strengthened by the camaraderie that developed among them, fueled by mutual

HIV touched something inside each of us that's more than the profession that we chose. It might be that keen interest in people's lives and wanting to talk to people and understand why they are what they are, and how they relate to their world, where they live, what they do. Maybe it was their stories. [In the early years] I was afraid that AIDS was just going to take over the world and what's going to happen? What brought solace to our lives was talking to the patients and that optimism of how they struggled and how they dealt with this, and how we helped them deal with it. I think in a way that kept our fear in check.

lieved, "We were going to solve this, and that was the commitment that kept me alive and kicking." Volberding, for his part, felt the pull of treating a disease that constantly challenged his competence: "The thrill of this was the care of these patients; they needed us so much. We couldn't cure or treat HIV effectively, but we managed a lot of problems."

Some credited the compelling characteristics of their patients with keeping them in the field. Pediatrician Hermann Mendez, who worked in Brooklyn, recalled, "You respected the people you were working with; you loved them, and need and professional succor. Most recalled forming friendships within the AIDS-care community because the "uninvolved" didn't understand what they were doing or why they were doing it.

Their inability to change the course of the disease forced doctors to seek other ways to meet patients' needs. Today, more than a decade after the introduction of antiretroviral therapy transformed the landscape of AIDS treatment, the memories these pioneers retain are vivid. Howard Grossman, who had a Manhattan-based private practice for gay men, recalled, "We got thrown back to an ear- they confronted went far beyond the clinical interventions they had been trained to provide. Gwendolyn Scott, a pediatric infectiousdisease specialist from Miami, remarked that she became a sort of social worker for affected families: "They were living in cars, they didn't have food, they didn't have roofs over their heads. I couldn't give them medical care when they didn't have a place to live and food to put in their mouths."

Of course, it was the tide of death during the epidemic's early years that left the most haunting memories. Although he had tried "to take pain and put it back in its own compartment," Volberding said, "there were horrible, horrible moments" during those years. Just as they strove to offer clinical care in the absence of effective medicine, many sought, in Friedland's words, "to arrange for a good death." Mendez was brought to tears as he recalled a young girl in Brooklyn who had died in the hospital just 1 hour after a brief reunion with her imprisoned mother: "We learned the lesson the hard way, how to allow them to die at home in their room with their siblings, with everybody understanding what is going on. From then on, we didn't and couldn't allow anybody to die in 
A patient of mine was admitted, blind and demented, because his AZT had worn off. I think that was the most depressing, horrifying experience of $m y$ whole career - having gone on that roller coaster, having been so excited, it was as if the whole bottom was just ripped out from under me, and there was nothing in sight that was really going to alter this.

— Donna Mildvan, Beth Israel Medical Center, New York

the hospital." El-Sadr recalled with anguish the surviving children of her patients and wondered what had happened to them. "Where are they now?" she asked. "Are they being taken care of? Are they healthy? Are they in jail?"

Commitments were tested in the late 1980s and early 1990s, not only by the emotional demands of a disease that mocked medicine's therapeutic aspirations but also by the dashed hopes for progress in attacking the underlying cause of AIDS. It was hard to forget the exhilaration many had felt when zidovudine (earlier known as azidothymidine, or AZT), the first antiretroviral drug, seemed to be effective. Alexandra Levine, an oncologist from Los Angeles, remembered a patient who had called because he had survived to celebrate his birthday. But it was also hard to forget the despair of learning that AZT's benefits matically than the startling aneven though I never thought would, with all the death and dying." Nothing underscored this ironic sense of nostalgia more dra- urgency that drew Oleske and his generation to the care of patients with AIDS in its early years no longer defines the world encountered by young doctors.

Some veterans of the U.S. epidemic have found their idealism revitalized by a commitment to the global epidemic. El-Sadr, for example, who has thrown herself into the struggle against AIDS in southern Africa, is "driven to make it happen there for all those people like we really did here. There are so many more similarities between Harlem and Maputo than there are between Harlem and San Francisco."

For others, the shifting of attention to the global epidemic implies that the challenge at home is no longer compelling. Oleske confronted that position directly, reminding his colleagues that AIDS remains embedded in America's poorest communities. "I'm not here to celebrate that HIV is over," were limited. Mildvan

said she found the experience personally painful and "professionally humbling."

With the development of effective antiretroviral therapy in the mid-1990s, many saw AIDS as having been normalized, rendered just another chronic disease. The crisis that had drawn these doctors and sustained their sense of mission had passed. For a few pioneers, this sense of mission retains something of its original excitement. Mildvan, for example, said, "This has never been a boring disease; it keeps evolving into

HIV care doesn't grab me and doesn't move me and doesn't excite me or challenge me the way it used to. So I, in fact, will be seeing my last HIV clinic on August 8, and I will no longer be doing HIV research or care. I'm happy for the patients, fortunately, that you can see them and say, "I'll see you in 4 months. Here's your lab slip. Here's your prescription refill." But for me, that doesn't speak to my need to be a healer, and it doesn't excite me the way it did at the very beginning, when there was so - Donald Abrams, San Francisco General Hospital, University of California, San Francisco

nouncement by Donald Abrams, a prominent gay physician and researcher in San Francisco, that he would be leaving HIV medicine imminently because it no longer spoke to his "need to be a healer."

Many of these pioneers feel that something has gone awry, and they despair about the next generation. "I'm not finding a lot of medical students and residents who want to do what I do," said Oleske. "They actually say, "This isn't for me.' I don't know how we're going to change that, but I worry very much." The sense of he concluded. "In Newark, New Jersey, AIDS is alive and well."

An interview with Drs. El Sadr and Oleske can be heard at www.nejm.org.

Dr. Bayer is a professor at the Center for the History and Ethics of Public Health, Department of Sociomedical Sciences, Mailman School of Public Health, Columbia University, New York. Dr. Oppenheimer is a professor in the Department of Health and Nutrition Sciences at Brooklyn College and the Graduate Center, City University of New York, and an associate professor of clinical public health in the Department of Sociomedical Sciences at the Mailman School of Public Health, Columbia University, New York.

1. Bayer R, Oppenheimer GM. AIDS doctors: voices from the epidemic. Oxford, England: Oxford University Press, 2000. 